11.1

\title{
Монолитный миниатюрный полосно-пропускающий фильтр на многопроводниковых полосковых резонаторах
}

\author{
() Б.А. Беляев ${ }^{1,2}$, А.М. Сержантов ${ }^{2}$, Ан.А. Лексиков ${ }^{1}$, Я.Ф. Бальва ${ }^{1}$, Р.Г. Галеев ${ }^{3}$ \\ ${ }^{1}$ Институт фоизики им. Л.В. Киренского СО РАН, Красноярск, Россия \\ ${ }^{2}$ Сибирский федеральный университет, Красноярск, Россия \\ ${ }^{3}$ Сибирский государственный университет науки и технологий им. М.Ф. Решетнева, \\ Красноярск, Россия \\ E-mail: belyaev@iph.krasn.ru
}

Поступило в Редакцию 25 марта 2021 г.

В окончательной редакции 25 марта 2021 г.

Принято к публикации 1 апреля 2021г.

Разработана новая монолитная конструкция миниатюрного полосно-пропускающего фильтра для изготовления по технологии многослойных печатных плат. Использование в конструкции многопроводниковых полосковых резонаторов обеспечивает не только миниатюрность, но и высокую избирательность устройства, что продемонстрировано на опытном образце фильтра четвертого порядка. Центральная частота полосы пропускания изготовленного фильтра $f_{0}=546 \mathrm{MHz}$, относительная ширина $\Delta f / f_{0}=25 \%$, вносимые потери $0.8 \mathrm{~dB}$. Фильтр обладает протяженной высокочастотной полосой заграждения, которая по уровню $-30 \mathrm{~dB}$ простирается до частоты $10 f_{0}$. Габариты фильтра $15.0 \times 12.0 \times 4.3 \mathrm{~mm}\left(0.027 \lambda_{0} \times 0.021 \lambda_{0} \times 0.007 \lambda_{0}\right.$, где $\lambda_{0}$ - длина волны в вакууме на частоте $f_{0}$ ), а масса составляет всего $1.8 \mathrm{~g}$. Характеристики фильтра и удобство конструкции для поверхностного монтажа доказывают его высокую перспективность.

Ключевые слова: полосно-пропускающий фильтр, многопроводниковый полосковый резонатор, технология многослойных печатных плат.

DOI: 10.21883/PJTF.2021.13.51115.18785

Как известно, важнейшими устройствами современных радиотехнических систем передачи, приема и обработки сигналов являются полосно-пропускающие фильтры, от которых зависит не только качество радиоаппаратуры, но и нередко ее габариты и даже цена. Поэтому разработка новых миниатюрных конструкций фильтров, обладающих высокими частотно-селективными свойствами и низкой стоимостью при массовом производстве, является важной и актуальной задачей. Для ее решения в настоящее время активно исследуются различные конструкции на полосковых резонаторах, в том числе и на многопроводниковых $[1,2]$, которые обладают не только рекордной миниатюрностью среди электродинамических резонаторов, но и сравнительно высокой собственной добротностью. Важно отметить, что в многослойном резонаторе с увеличением числа проводников и уменьшением толщины диэлектрических прослоек его добротность растет, а размеры уменьшаются [2]. Однако при увеличении числа проводников резонансы высших мод колебаний монотонно понижаются, приближаясь к резонансу первой рабочей моды колебаний. Это уменьшает как ширину высокочастотной полосы заграждения фильтра, так и величину затухания в ней, что, очевидно, ухудшает его частотно-селективные свойства, особенно сильно у фильтров с широкими полосами пропускания.

В настоящей работе указанная выше проблема многопроводникового резонатора решается специальным соединением его четных или нечетных проводников вблизи их свободных концов. Фильтры на таких резонаторах изготавливаются по технологии многослойных печатных плат (printed circuit board, РCВ), которая широко применяется для создания различных микроэлектронных устройств, в том числе и фильтров, как правило, традиционных конструкций $[3,4]$. Положительным моментом применения технологии РСВ для изготовления многопроводниковых резонаторов является возможность уменьшения вносимого затухания в полосе пропускания фильтров по сравнению с затуханием в более миниатюрных LTCC-устройствах [5-7] при использовании тонких диэлектрических слоев и медных проводников [8]. Кроме того, РСВ-технология в своем развитии достигла высокой точности позиционирования проводников в многослойных структурах при возможности одновременного изготовления множества устройств на большой площади структуры. Это существенно снижает стоимость фильтров при их массовом производстве по РСВ-технологии в сравнении с другими технологиями изготовления миниатюрных устройств.

Конструкция исследуемого монолитного фильтра на многопроводниковых полосковых резонаторах показана на рис. 1. Каждый резонатор фильтра образован шестью полосковыми проводниками, расположенными друг над другом и разделенными тонкими диэлектрическими слоями. Проводники одним концом соединены с экраном (через один на противоположных сторонах корпуса-экрана). Роль корпуса-экрана выполняют металлизированные химическим осаждением меди с фи- 


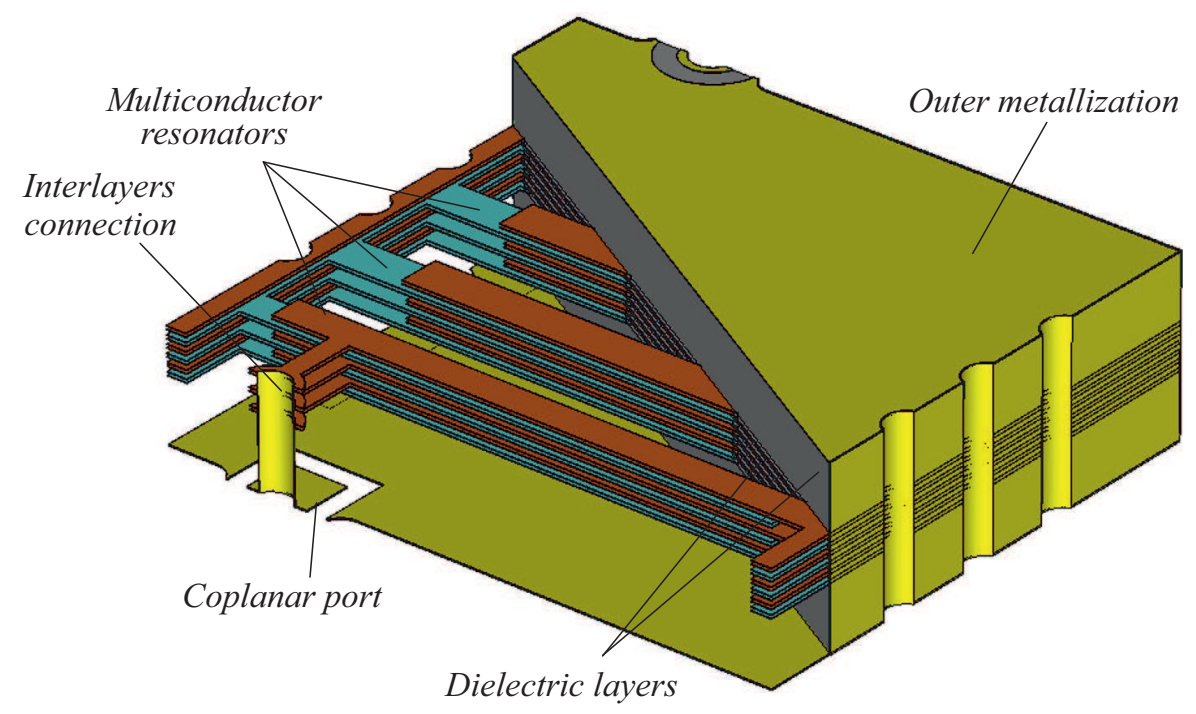

Pис. 1. Конструкция монолитного фильтра на многопроводниковых полосковых резонаторах.

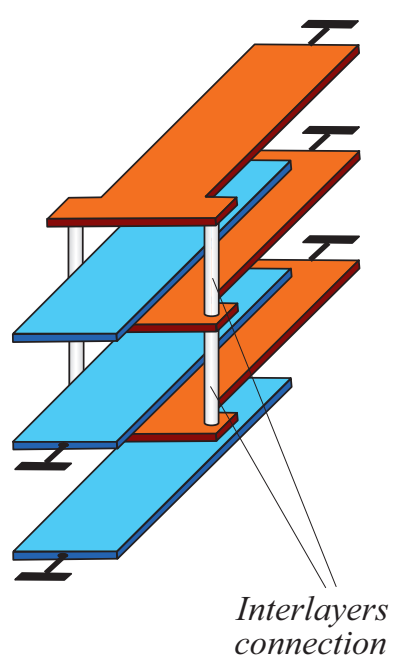

$a$

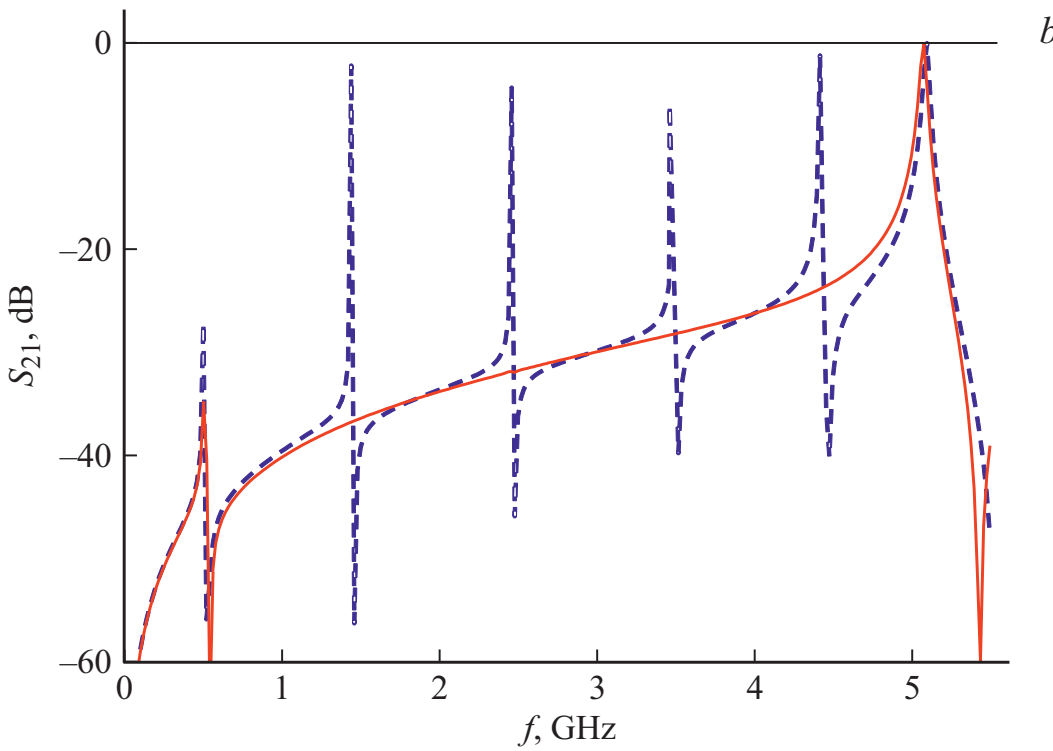

Рис. 2. $a-$ конструкция шестипроводникового резонатора с перемычками между несоседними проводниками; $b-$ его спектр собственных частот (сплошная линия), штриховая линия - спектр частот этого резонатора без перемычек.

нальным золочением наружные поверхности многослойной структуры. Принципиальным отличием исследуемой конструкции от известных решений является наличие соединений четных или нечетных проводников крайних резонаторов фильтра посредством сквозных металлизированных цилиндрических отверстий, разрезанных вдоль оси по диаметру, как показано на рис. 1. Металлизация отверстий служит центральным проводником отрезков копланарных линий, являющихся входным и выходным портами фильтра, удобными для поверхностного монтажа устройства.

Докажем преимущество многопроводникового резонатора, состоящего, например, из шести полосковых проводников (рис. 2,a), в котором свободные концы несмежных проводников (через один) соединены друг с другом проволочными перемычками. Чтобы не загромождать рисунок, на нем не показаны диэлектрические слои. На рис. 2, $b$ сплошной линией представлена рассчитанная амплитудно-частотная характеристика (АЧХ) рассматриваемого резонатора, подключенного со слабой связью к линиям передачи, а штриховой линией показана АЧХ этого резонатора без перемычек (с разъединенными концами полосковых проводников). Расчет проведен путем электродинамического анализа 3D-моделей резонаторов в пакете программ „CST Studio Suite“, при этом считалось, что пять диэлектрических прослоек между 

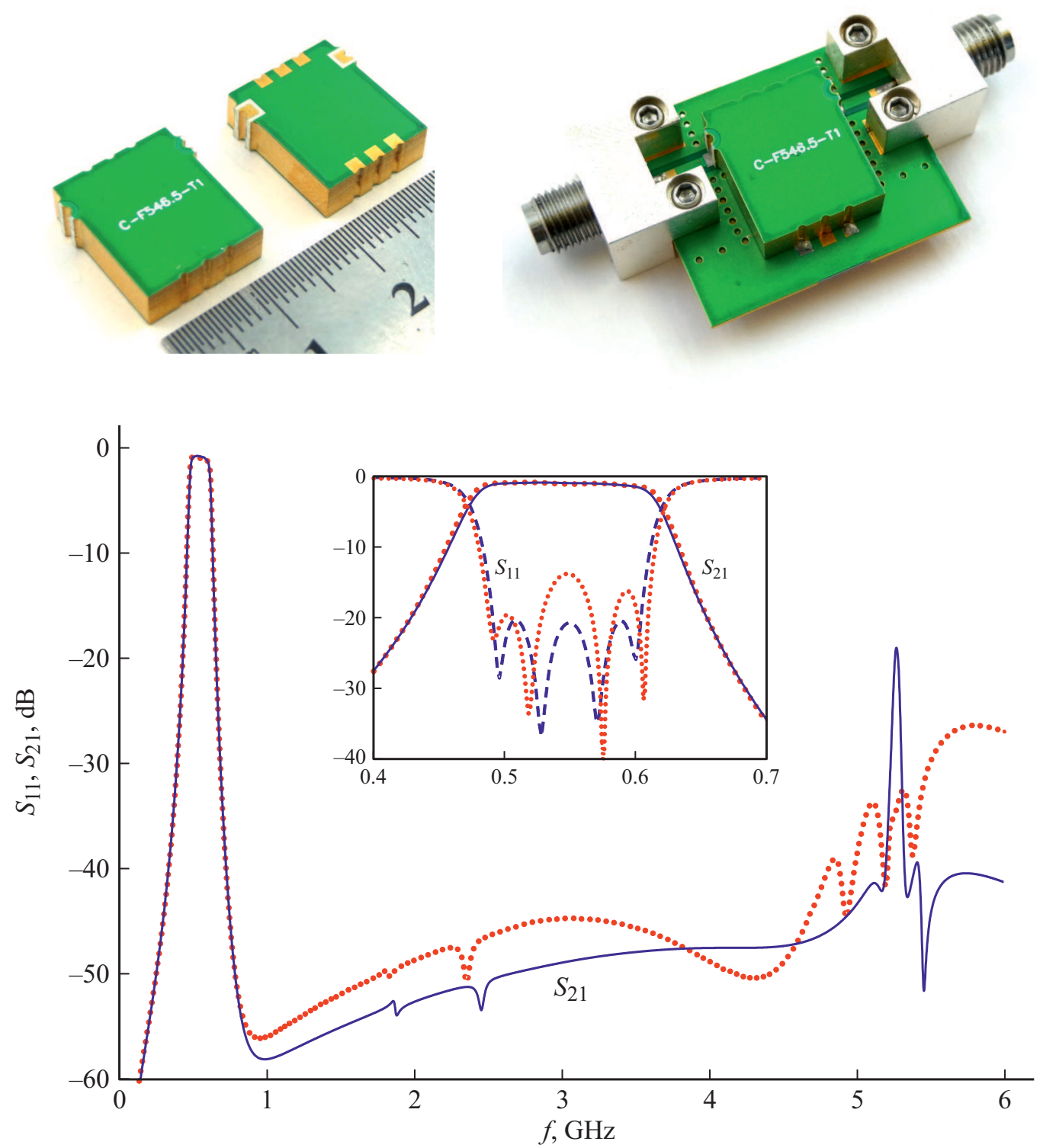

Рис. 3. Фотографии опытного образца монолитного фильтра (вид сверху, снизу и в измерительном держателе), а также его АЧХ. Сплошная и штриховая линии - расчет, пунктир - эксперимент.

проводниками из материала $\mathrm{RO} 4350 \mathrm{~B}^{\mathrm{TM}}$ с относительной диэлектрической проницаемостью $\varepsilon=3.48$ имели толщину $h_{1}=0.102 \mathrm{~mm}$, а два наружных слоя из такого же материала имели толщину $h_{2}=1.524 \mathrm{~mm}$. Ширина всех полосковых проводников структуры $1 \mathrm{~mm}$, их длина $13.1 \mathrm{~mm}$, полная длина резонатора $15 \mathrm{~mm}$.

На АЧХ резонатора без перемычек (штриховая линия на рис. 2,b) видны шесть резонансов, соответствующих шести модам колебаний системы из шести сильно связанных четвертьволновых резонаторов. Самому нижнему резонансу соответствует мода колебаний, для которой токи во всех проводниках имеют одинаковое направление, а заряды на свободных концах соседних проводников имеют противоположные знаки, как и в случае сильно связанных четвертьволновых микрополосковых резонаторов, образующих встречно-штыревую структуpy $[9,10]$. Включение перемычек между несмежными полосковыми проводниками практически не влияет на резонансные частоты первой и шестой мод колебаний, так как для этих мод заряды на всех замкнутых проводниках имеют одинаковые знаки. Однако эти перемычки исключают возбуждение резонансов остальных четырех мод колебаний, так как для них в зависимости от номера моды на всех замкнутых перемычками проводниках или на их части заряды имеют противоположные знаки. Таким образом, в конструкции многопроводникового резонатора с перемычками в несколько раз увеличивается различие частот первых двух резонансов, соответствующих первой и шестой модам колебаний резонатора без перемычек. В результате у фильтра на таких резонаторах 
не только соответственно расширяется высокочастотная полоса заграждения, но и повышается уровень затухания в ней. Очевидно, что разрежение спектра резонансов собственных мод колебаний в многопроводниковых резонаторах с перемычками между несоседними проводниками будет наблюдаться в резонаторах с любым числом проводников, бо́льшим трех.

Для экспериментальной проверки работоспособности предложенной конструкции фильтра четвертого порядка (рис. 1), каждый резонатор которого образован шестью полосковыми проводниками, предварительно был проведен параметрический синтез устройства с использованием электродинамического анализа его 3D-модели в пакете программ „CST Studio Suite“. Параметры диэлектрических слоев фильтра были такими же, как указанные выше для исследованного резонатора (рис. 2,a). Для определенности ширина проводников внутренних резонаторов составляла $1 \mathrm{~mm}$, а наружных $-0.8 \mathrm{~mm}$. При синтезе была задана центральная частота полосы пропускания фильтра $f_{0}=545 \mathrm{MHz}$ и ее относительная ширина по уровню $-3 \mathrm{~dB} \Delta f / f_{0}=25 \%$.

В результате синтеза были найдены остальные конструктивные параметры устройства, в частности величина зазора между парой внутренних резонаторов $(1.64 \mathrm{~mm})$ и между парами наружных резонаторов $(1.93 \mathrm{~mm})$. По полученным параметрам с использованием технологии многослойных печатных плат с применением фотолитографии был изготовлен опытный образец монолитного фильтра, фотографии которого представлены на рис. 3. Размеры фильтра составляют $15.0 \times 12.0 \times 4.3 \mathrm{~mm}$ или в длинах волн в вакууме на центральной частоте полосы пропускания $0.027 \lambda_{0} \times 0.021 \lambda_{0} \times 0.007 \lambda_{0}$, масса фильтра всего $1.8 \mathrm{~g}$. Измеренные частотные зависимости прямых $S_{21}(f)$ и обратных $S_{11}(f)$ потерь экспериментального образца фильтра показаны пунктиром на рис. 3, а сплошной и штриховой линиями представлены расчетные зависимости, полученные в результате параметрического синтеза устройства. Приведенные на рис. 3 зависимости демонстрируют хорошее согласие расчета и эксперимента.

Центральная частота полосы пропускания опытного образца фильтра $f_{0}=546 \mathrm{MHz}$, а относительная ширина полосы пропускания, измеренная по уровню $-3 \mathrm{~dB}, \Delta f / f_{0}=25 \%$. Минимальное вносимое затухание в полосе пропускания фильтра составило всего $0.8 \mathrm{~dB}$, а максимальный уровень отражений в полосе пропускания $-15 \mathrm{~dB}$. Высокочастотный край полосы заграждения по уровню $-30 \mathrm{~dB}$ простирается до частоты $10 f_{0}$. Важно отметить, что аналогичный фильтр без межслойных соединений имеет протяженность полосы заграждения по такому же уровню всего $2.2 f_{0}$.

Таким образом, в работе исследована новая миниатюрная конструкция полоскового полосно-пропускающего фильтра в монолитном исполнении, изготовленная с применением технологии многослойных печатных плат.
Корпус фильтра образуют металлизированные химическим осаждением меди с финальным золочением наружные поверхности многослойной структуры. Миниатюрность и высокие частотно-селективные свойства фильтра достигнуты благодаря использованию многопроводниковых полосковых резонаторов, в которых несоседние проводники соединены между собой посредством сквозных металлизированных цилиндрических отверстий. Металлизация отверстий служит центральным проводником отрезков копланарных линий, являющихся входным и выходным портами фильтра, удобными для поверхностного монтажа устройства. Измеренные характеристики изготовленного опытного образца фильтра четвертого порядка хорошо согласуются с характеристиками, полученными при параметрическом синтезе устройства. Все изложенное выше доказывает перспективность использования разработанной конструкции фильтра в различных радиотехнических системах.

\section{Финансирование работы}

Работа выполнена при финансовой поддержке Министерства науки и высшего образования РФ в ходе реализации комплексного проекта „Создание высокотехнологичного производства земных станций перспективных систем спутниковой связи для обеспечения связанности труднодоступных, северных и Арктических территорий Российской Федерации“, осуществляемого при участии ФИЦ КНЦ СО РАН (соглашение № 075-11-2019-078 от 13.12.2019).

\section{Конфликт интересов}

Авторы заявляют, что у них нет конфликта интересов.

\section{Список литературы}

[1] B.A. Belyaev, A.M. Serzhantov, A.A. Leksikov, Ya.F. Bal'va, An.A. Leksikov, IEEE Microwave Wireless Components Lett., 25 (9), 579 (2015). DOI: 10.1109/LMWC.2015.2451363

[2] B.A. Belyaev, A.M. Serzhantov, A.A. Leksikov, Y.F. Bal'va, An.A. Leksikov, Microwave Opt. Technol. Lett., 59 (9), 2212 (2017). DOI: 10.1002/mop.30706

[3] M. Cariou, B. Potelon, C. Quendo, S. Cadiou, E. Schlaffer, W. Pessl, A.L. Fevre, IEEE Trans. Microwave Theory Techn., 65 (2), 496 (2017). DOI: 10.1109/TMTT.2016.2632114

[4] Z.-C. Hao, W. Ding, W. Hong, IEEE Trans. Microwave Theory Techn., 64 (6), 1775 (2016). DOI: 10.1109/TMTT.2016.2553029

[5] Y. Imanaka, Multilayered low temperature cofired ceramics (LTCC) technology (Springer Science+Business Media, Inc., 2005). DOI: $10.1007 / \mathrm{b} 101196$

[6] И.Б. Вендик, Д.В. Холодняк, А.В. Симин, Компоненты и технологии, № 5, 190 (2005). 
[7] D. Kholodnyak, Ya. Kolmakov, I. Vendik, J.F. Trabert, J. Mueller, K.-H. Druee, M.A. Hein, in Proc. of the 38th European Microwave Conf. (Amsterdam, 2008), p. 211.

DOI: 10.1109/EUMC.2008.4751425

[8] A.M. Maric, G.J. Radosavljevic, W. Smetana, L.D. Zivanov, Microelectron. Int., 31 (1), 32 (2014).

DOI: 10.1108/MI-04-2013-0017

[9] Б.А. Беляев, А.М. Сержантов, Я.Ф. Бальва, А.А. Лексиков, Р.Г. Галеев, Письма в ЖТФ, 40 (22), 52 (2014).

[10] Б.А. Беляев, А.М. Сержантов, Я.Ф. Бальва, Ан.А. Лексиков, Р.Г. Галеев, Письма в ЖТФ, 41 (10), 89 (2015). 